University of Nebraska - Lincoln

DigitalCommons@University of Nebraska - Lincoln

2003

\title{
Optimization Model Estimates of Trunk Muscle Forces Do Not Correlate With EMG Activity of Females as Well as Males
}

\author{
Mark L. McMulkin \\ Shriners Hospitals for Children, Spokane, WA \\ Jeffrey C. Woldstad \\ University of Nebraska - Lincoln, Jeffrey.Woldstad@sdsmt.edu \\ Richard E. Hughes \\ 3University of Michigan
}

Follow this and additional works at: https://digitalcommons.unl.edu/imsefacpub

Part of the Operations Research, Systems Engineering and Industrial Engineering Commons

McMulkin, Mark L.; Woldstad, Jeffrey C.; and Hughes, Richard E., "Optimization Model Estimates of Trunk Muscle Forces Do Not Correlate With EMG Activity of Females as Well as Males" (2003). Industrial and Management Systems Engineering Faculty Publications. 3.

https://digitalcommons.unl.edu/imsefacpub/3

This Article is brought to you for free and open access by the Industrial and Management Systems Engineering at DigitalCommons@University of Nebraska - Lincoln. It has been accepted for inclusion in Industrial and Management Systems Engineering Faculty Publications by an authorized administrator of DigitalCommons@University of Nebraska - Lincoln. 


\title{
Optimization Model Estimates of Trunk Muscle Forces Do Not Correlate With EMG Activity of Females as Well as Males
}

\author{
Mark L. McMulkin ${ }^{1}$, Jeffrey C. Woldstad", and Richard E. Hughes ${ }^{3}$ \\ 'Shriners Hospitals for Children-Spokane; ${ }^{2}$ Oregon State University; \\ ${ }^{3}$ University of Michigan
}

\begin{abstract}
Biomechanical optimization models are often used to estimate muscular and intervertebral disc forces during physical exertions. The purpose of this study was to determine whether an optimization-based biomechanical model predicts torso muscular activity of males and females equally well. The Minimum Intensity Compression (MIC) model, which has been extensively applied in industrial ergonomic task analysis, was used to estimate muscle forces for 3D moments. Participants $(6 \mathrm{M}, 6 \mathrm{~F})$ performed 18 isometric exertions resisting 3D L3/L4 moments while electromyographic (EMG) activity was recorded for 8 muscles. Overall, model force estimates correlated better with male EMG activity $\left(R^{2}=0.43\right)$ than with female EMG activity $\left(R^{2}=0.33\right)$. Model force estimates of 4 muscles (LRA, RRA, REO, and RES) correlated better with male EMG activity than with female EMG. We conclude that trunk muscle forces estimated by current biomechanical modeling do not correlate equally well to male and female EMG activity. Future research needs to address validation or improvement of biomechanical trunk models for females.
\end{abstract}

Key Words: muscle line of action, spine, gender, women

\section{Introduction}

Manual material handling tasks are often evaluated using biomechanical models that estimate trunk muscular forces which are large contributors to lumbar spinal forces. Computer models for job analysis (e.g., the 3D SSPP software developed at the University of Michigan) are widely available for ergonomic job analysis and use the optimization method, Minimum Intensity Compression model (MIC; Bean,

M.L. McMulkin is with the Motion Analysis Lab, Shriners Hospitals for Children, 911 W. 5th Ave., Spokane, WA 99210-2472; J.C. Woldstad is with the Industrial and Manufacturing Engineering Dept., Oregon State Univ., Corvallis, OR 97331; R.E. Hughes is with the Orthopaedic Research Labs, Univ. of Michigan, Ann Arbor, MI 48109. 
Chaffin, \& Schultz, 1988) to predict multiple muscle forces from 3D external moments calculated at a single cutting plane. The optimization-model approach is commonly used for ergonomic job analysis because it has low data requirements and does not necessitate the use of electromyography (EMG) instrumentation in the workplace. Muscle parameters (muscle moment arms, lines of action, and crosssectional areas) typically employed by biomechanical models are based largely on male data. It is unclear whether the MIC model will work equally well when applied to both males and females performing trunk exertions.

Today, health policy makers are emphasizing women's health, including health in the workplace. For example, in the United States, the National Institutes of Health have established the Office of Research on Women's Health. Its purpose is to promote, stimulate, and support efforts to improve the health of women through biomedical research with the mandates of increasing research into diseases, disorders, and conditions that affect women, and to ensure that women are included as participants in NIH-supported research. Therefore, low-back biomechanical modeling techniques that use male-based data as inputs do not reflect recent trends in biomedical research. In addition, previous validations of low-back biomechanical models have included a limited number of female participants in experimental research protocols (Cholewicki, McGill, \& Norman, 1995; Hughes \& Chaffin, 1995; Hughes, Chaffin, Lavender, \& Andersson, 1994; Ladin, Murthy, \& De Luca, 1989; Schultz, Cromwell, Warwick, \& Andersson, 1987; Schultz, Haderspeck, Warwick, \& Portillo, 1983; Zetterberg, Andersson, \& Schultz, 1987).

The purpose of this study was to assess whether muscle force estimates from the MIC optimization-based model correlate equally well with EMG activity measured in males and females during trunk exertion activities. If the muscle forces estimated by the MIC model with inputs based on male data do not correlate equally well with actual male and female muscle activity, future modeling techniques need to focus on improving the analysis for both genders.

\section{Methods}

Six young men and 6 young women participated in this study. Mean height, mass, and age of the men were $174.3 \mathrm{~cm}( \pm 4.4 S D), 66.1 \mathrm{~kg}( \pm 6.2)$, and 21.3 years $( \pm 3.6)$, respectively. Mean height, mass, and age of the women were $171.4 \mathrm{~cm}( \pm 6.0)$, $64.0 \mathrm{~kg}( \pm 6.58)$, and 21.0 years $( \pm 2.8)$, respectively. Informed consent was obtained from all participants with the protocol approved by the Institutional Review Board of Virginia Polytechnic Institute and State University.

Participants completed 18 isometric physical exertions consisting of 3D moments. The 18 exertions were selected to manipulate flexion/extension and lateral bending moments while applying a constant torsion moment. The magnitude of the projection of the resultant moment vector onto the flexion/extension-lateral bending plane was $30 \mathrm{Nm}$, and the torsion component was $7.5 \mathrm{Nm}$. Therefore the resultant moment magnitude for each trial was $30.9 \mathrm{Nm}$. For example, in Condition 1 the participants attempted $30 \mathrm{Nm}$ flexion, $0 \mathrm{Nm}$ lateral bending, and $7.5 \mathrm{Nm}$ torsion; Condition 2 had $28.2 \mathrm{Nm}$ attempted flexion, $10.3 \mathrm{Nm}$ left lateral bending, and $7.5 \mathrm{Nm}$ torsion; Condition 10 had $30 \mathrm{Nm}$ attempted extension, $0 \mathrm{Nm}$ lateral bending, and 7.5 Nm torsion; and so on until Condition $18 \mathrm{had} 28.2 \mathrm{Nm}$ attempted flexion, 10.3 $\mathrm{Nm}$ right lateral bending, and $7.5 \mathrm{Nm}$ torsion. 


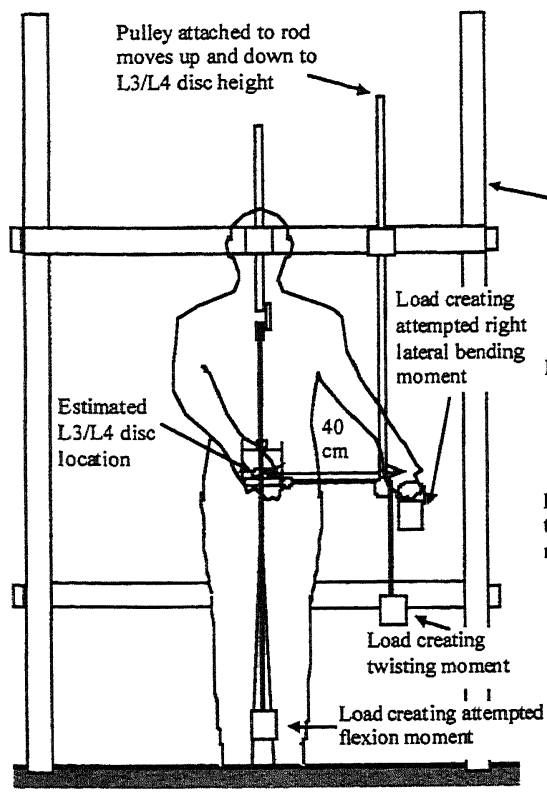

(a) Front View of Loading Apparatus

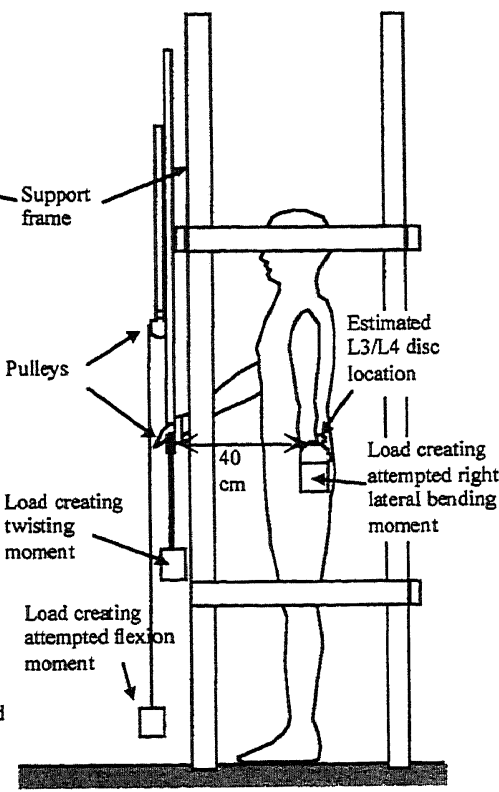

(b) Side View

Figure 1-Apparatus used to generate 3D isometric moments resisted by participants in this experiment.

To create the moments, the participants held weights in their hands while standing in a frame (Figure 1). Attempted flexion moments (external extension moments) were created by holding a handle connected by a cable to a weight suspended over a pulley attached to the frame. The handle was located $40 \mathrm{~cm}$ anterior to the estimated disc center (Tracy, Gibson, Szypryt, Rutherford, \& Corlett, 1989 ) at the level of the L3/L4. Attempted extension moments (external flexion moments) were created by using one hand to hold a weight off the floor in front of the body. The lateral bending moments were created by holding a weight $40 \mathrm{~cm}$ laterally from the $\mathrm{L} 3 / \mathrm{L} 4$ disc in the transverse plane. Torsion moments were generated by attaching a weight to the handle (via a cable over a pulley) in line with the grip at the L3/L4 disc level. Markers suspended from the frame in front and to the side at L3/L4 level indicated the absolute positions where the hands were held. To help stabilize the lower extremity, the participants wore a hip belt tethered by straps to the four posts of the loading frame.

To account for individual differences in arm masses and positions between participants, different weights were applied over the pulleys or were lifted for each person so that equal moments were resisted across participants. Moments at the L3/L4 disc due to the weight of the arms were determined using measurements of lower and upper link lengths and center-of-gravity estimates (Clauser, McConville, \& Young, 1969), link weights were estimated as percentages of total body weight (Webb Associates, 1978), and positioning was determined from videotaping. To ensure that the participants maintained consistent trunk posture while external loads 
were applied, light emitters were mounted in front of and behind them at suprasternale height. The light beam was directed in a plane parallel to the frontal plane so that flexion, extension, or twisting of the trunk broke the beam. If participants had lateral bending, the wider trunk depth inferior to the suprasternale level blocked the beams. Participants adjusted their posture until both lights reflected back to the sensors, and LEDs in front of the participants lit up to indicate an upright posture.

During physical exertions, EMG activity of four muscle pairs were recorded by electrode pairs at positions used by McGill (1991): LES and RES, $3 \mathrm{~cm}$ from midline at L3 spinous process level; LRA and RRA, $3 \mathrm{~cm}$ from midline at the umbilicus level; LLD and RLD, over the muscle belly at T9 level; LEO and REO, $6 \mathrm{~cm}$ dorsal to the ASIS at the umbilicus level (Pope, Andersson, Broman, Svensson, $\&$ Zetterberg, 1986). An electrode was placed on the right acromion as the ground. Six maximum voluntary contraction (MVC) trials described by McGill (1991) were conducted to elicit the maximum EMG for the muscles under study. The muscle resting EMG level was measured as the participant lay on a bench. After amplification, the raw EMG signals were sampled at $500 \mathrm{~Hz}$ and then high-pass filtered using a 30-Hz cutoff (Redfern, Hughes, \& Chaffin, 1993). The EMG data were processed by taking the root mean square (RMS) with a 60 -ms time constant. The mean RMS values for each trial were normalized (Lavender, Tsuang, Hafezi, et al., 1992; Mirka, 1991) to get percent muscle activity using the equation

$$
\mathrm{EMG}_{\text {Normalized }}=\frac{E M G_{\text {Test Trial }}-\mathrm{EMG}_{\text {Resting }}}{E M G_{\text {Max }}-\mathrm{EMG}_{\text {Resting }}} \times 100
$$

The participants completed the exertions in a randomly ordered sequence. They were required to resist the moments for 3 seconds while the EMG signals were collected. They were given 2-minute rest breaks between trials.

The L3/L4 applied moments were used as inputs to the MIC model (Bean et al., 1988). Five bilateral muscle pairs (erector spinae, rectus abdominis, latissimus dorsi, external oblique, and internal oblique) were included in the model with crosssectional areas, moment arms, and lines of action tabulated by Hughes et al. (1994).

The percent muscle activity $\left(\mathrm{EMG}_{\text {Normalized }}\right)$ was correlated with the model's muscle force estimates. The muscle force estimated by the model was used as the regressor variable to predict percent muscle activity measured in the experiment for each person individually. $R^{2}$ values were then averaged across participants by gender and muscle. A linear model was assumed between model muscle force and measured muscle activity. EMG signals were not used to predict muscle tension; they were correlated to model estimations of muscle force. The static moments resisted were at a relatively low level, thus linearity was not assumed for the entire force range (Chaffin \& Andersson, 1991).

\section{Results}

Muscle forces estimated by the MIC model did not correlate equally well with male and female EMG data. Across all muscles, forces estimated by the MIC model correlated better with male EMG activity (mean $R^{2}=0.44$ ) than with female EMG activity (mean $R^{2}=0.33$ ). When individual muscles were analyzed, correlations were better for males than for females for the RRA, LRA, REO, and RES by 10 to 
Table $1 R^{2}$ Values for Regressions Relating Muscle EMG Activity (in \%MVC) and Model Force Estimates $(\mathbf{N}) *$

\begin{tabular}{lll}
\hline & \multicolumn{2}{c}{ Gender } \\
Muscle & Female & Male \\
\hline Left rectus abdominis (LRA) & 0.53 & 0.64 \\
Right rectus abdominis (RRA) & 0.43 & 0.80 \\
Left external oblique (LEO) & 0.34 & 0.38 \\
Right external oblique (REO) & 0.20 & 0.30 \\
Left latissimus dorsi (LLD) & 0.11 & 0.13 \\
Right latissimus dorsi (RLD) & 0.03 & 0.03 \\
Left erector spinae (LES) & 0.53 & 0.54 \\
Right erector spinae (RES) & 0.46 & 0.58 \\
\hline
\end{tabular}

*Regressions determined for 12 participants and 8 muscles were then averaged by gender for mean values.

$37 \%$ (Table 1). Muscle force estimated by the model that followed the pattern of activity and inactivity of measured muscle activity for individuals had higher $R^{2}$ values in the regression equations (Figure 2). For example, the RRA of Participant 5 (Figure 2) was inactive during attempted extension moments and zero force had already been predicted by the model for the RRA.

\section{Discussion}

This study addressed the following question: Can the MIC optimization-based model be equally applied to males and females during trunk exertion activities? The results indicated that the MIC model cannot be equally applied to both genders during trunk exertions because muscle force estimates from the model correlate better with male EMG activity than with female EMG activity. More specifically, the model muscle forces correlated with EMG activity of four muscles better for males than for females: RRA, LRA, REO, and RES.

Comparing the results of the current study to previous studies was difficult because none have included moments about all three axes or compared estimates to both genders. Hughes et al. (1994) and Hughes and Chaffin (1995) compared model predictions of the MIC to actual activity during resistance of moments about two axes. Hughes et al. (1994) generally found higher $R^{2}$ values (but showed the same trends as the current study) due to two possible reasons: (1) the $R^{2}$ values were for mean muscle activity across participants, while the current study predicted individual muscle activity (and then mean $R^{2}$ was calculated), and (2) Hughes et al. used only male participants (the current study indicates that male muscle activity predicted better). Disagreement with previously published work may also be due to the method of torso loading, as loading the hands has been shown to produce different EMG activation than loading using a chest harness (McMulkin, Woldstad, \& Hughes, 1998). 

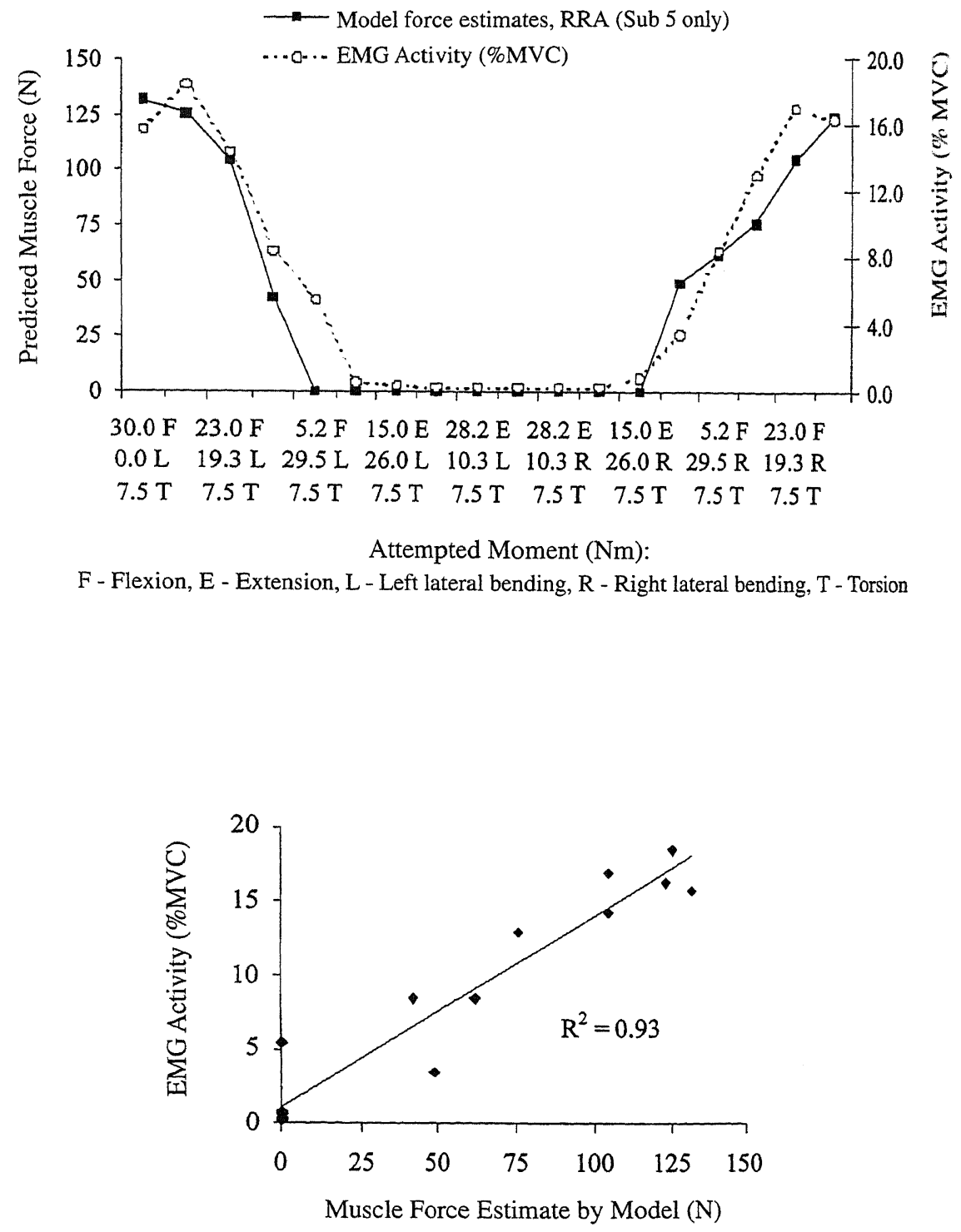

Figure 2 - Muscle force of RRA estimated by model and actual EMG activity (Participant 5 only). Top panel: Solid line represents model estimates of muscle force $(\mathrm{N})$ and are scaled to the left ordinate axis. EMG muscle activity, the dashed line, is in percentage of maximum and is scaled to the ordinate axis on the right. Since model estimates are in N and EMG is in percent, a single scale cannot be used. Bottom panel: Regression lines relating EMG muscle activity and model muscle force estimates using the same data as in the top panel. Using model force estimates to predict percent EMG activity, $R^{2}=0.93$. 
Trunk muscle cross-sectional areas and moment arms have been reported for females (Chaffin, Redfern, Erig, \& Goldstein, 1990; Jorgensen, Marras, Granata, \& Wiand, 2001; Marras, Jorgensen, Granata, \& Wiand, 2001). Trunk muscle lines of action were not reported with these data sets. For the current study, the MIC optimization model was formulated using female-specific trunk muscle crosssectional areas and moment arms (Jorgensen et al., 2001; Marras et al., 2001) combined with lines of action tabulated by Hughes et al. (1994). Model force estimates still correlated better with the EMG activity of males than that of females. Therefore, female trunk-muscle lines of action would still seem to be a critical component. Alternative modeling techniques such as the EMG-assisted approach (McGill \& Norman, 1986; Nussbaum \& Chaffin, 1998; Reilly \& Marras, 1989) still require the same muscle parameter inputs and would likely be affected by the lack of gender-specific muscle geometry.

There were several limitations in the model development and experimentation used in the present study. First, 10 muscles were included in the model formulations to represent the internal force-generating components of the lumbar region of the torso. Second, only young healthy participants were used in the study. Third, all model estimates and physical exertions were for isometric loading tasks at relatively low levels. Fourth, flexion/extension and lateral bending moments were generated simultaneously by participants holding weights in front and to the sides, $90^{\circ}$ apart. Also, industrial tasks are typically composed of physical exertions involving a single load, but the current experimental setup had the advantage of maintaining consistent moments across participants.

We conclude that the application of trunk biomechanical models to estimate female muscle activity should be considered carefully. In general, more extensive research is needed on trunk muscle parameters, given that the existing data is based largely on males and on low numbers of study participants. Future research needs to address validation and improvement of biomechanical trunk models for females.

\section{References}

Bean, J.C., Chaffin, D.B., \& Schultz, A.B. (1988). Biomechanical model calculation of muscle contraction forces: A double linear programming method. Journal of Biomechanics, 21, 59-66.

Chaffin, D.B., \& Andersson, G.B.J. (1991). Occupational biomechanics. New York: Wiley \& Sons.

Chaffin, D.B., Redfern, M.S., Erig, M., \& Goldstein, S.A. (1990). Lumbar muscle size and locations from CT scans of 96 women of age 40 to 63 years. Clinical Biomechanics, 5, 9-16.

Cholewicki, J., McGill, S.M., \& Norman, R.W. (1995). Comparison of muscle forces and joint load from an optimization and EMG assisted lumbar spine model: Towards development of a hybrid approach. Journal of Biomechanics, 28, 321-331.

Clauser, C.W., McConville, J.T., \& Young, J.W. (1969). Weight, volume, and centers of mass segments of the human body [Tech. Report AMRL-TR-69-70]. Wright-Patterson AFB, OH: Aerospace Medical Research Labs.

Hughes, R.E., \& Chaffin, D.B. (1995). The effect of strict muscle stress limits on abdominal muscle force predictions for combined torsion and extension loadings. Journal of Biomechanics, 28, 527-533. 
Hughes, R.E., Chaffin, D.B., Lavender, S.A., \& Andersson, G.B.J. (1994). Evaluation of muscle force prediction models of the lumbar trunk using surface electromyography. Joumal of Orthopaedic Research, 12, 689-698.

Jorgensen, M.J., Marras, W.S., Granata, K.P., \& Wiand, J.W. (2001). MRI-derived momentarms of the female and male spine loading muscles. Clinical Biomechanics, 16, 182193.

Ladin, Z., Murthy, K.R., \& De Luca, C.J. (1989). Mechanical recruitment of low-back muscles: Theoretical predictions and experimental validation. Spine, 14, 927-938.

Lavender, S.A., Tsuang, Y.H., Hafezi, A., Andersson, G.B.J., Chaffin, D.B., \& Hughes, R.E. (1992). Coactivation of the trunk muscles during asymmetric loading of the torso. Human Factors, 34, $239-247$.

Marras, W.S, Jorgensen, M.J., Granata, K.P., \& Wiand, B. (2001). Female and male trunk geometry: Size and prediction of the spine loading trunk muscles derived from MRI. Clinical Biomechanics, 16, 38-46.

McGill, S.M. (1991). Electromyographic activity of the abdominal and low back musculature during the generation of isometric and dynamic axial truck torque: Implications for lumbar mechanics. Journal of Orthopaedic Research, 9, 91-103.

McGill, S.M., \& Norman, R.W. (1986). Partitioning of the L4-L5 dynamic and moment into disc, ligamentous, and muscular components during lifting. Spine, 11, 666-678.

McMulkin, M.L, Woldstad, J.C., \& Hughes, R.E. (1998). Torso loading via a harness method activates trunk muscles less than a hand loading method. Journal of Biomechanics, 31, 391-395.

Mirka, G.A. (1991). The quantification of EMG normalization error. Ergonomics, 34, 343352.

Nussbaum, M.A., \& Chaffin, D.B. (1998). Lumbar muscle force estimation using a subjectinvariant 5-parameter EMG-based model. Journal of Biomechanics, 31, 667-672.

Pope, M.H., Andersson, G.B.J., Broman, H., Svensson, M., \& Zetterberg, C. (1986). Electromyographic studies of the lumbar trunk musculature during the development of axial torques. Journal of Orthopaedic Research, 4, 288-297.

Redfern, M.S., Hughes, R.E., \& Chaffin, D.B. (1993). High-pass filtering to remove electrocardiographic interference from torso EMG recordings. Clinical Biomechanics, 8, 44-48.

Reilly, C.H., \& Marras, W.S. (1989). Simulift: A simulation model of human trunk motion. Spine, 14, 5-11.

Schultz, A., Cromwell, R., Warwick, D., \& Andersson, G. (1987). Lumbar trunk muscle use in standing isometric heavy exertions. Journal of Orthopaedic Research, 5, 320-329.

Schultz, A.B., Haderspeck, K., Warwick, D., \& Portillo, D. (1983). Use of lumbar trunk muscles in isometric performance of mechanically complex standing tasks. Journal of Orthopaedic Research, 1, 77-91.

Tracy, M.F., Gibson, M.J., Szypryt, E.P., Rutherford, A., \& Corlett, E.N. (1989). The geometry of the muscles of the lumbar spine determined by magnetic resonance imaging. Spine, 14, 186-193.

Webb Associates (1978). Anthropometric source book Volume I: Anthropometry for designers [NASA Reference Publ. 1024]. Washington, DC: National Aeronautics and Space Administration.

Zetterberg, C., Andersson, G.B.J., \& Schultz, A.B. (1987). The activity of individual trunk muscles during heavy physical loading. Spine, 12, 1035-1040. 